\title{
VIDEOCOLUMNISMO. Desafíos para el periodismo de opinión
}

\author{
Cesar Augusto Gaviria Cuartas * \\ Diego Alberto Polo Paredes** \\ DOI: https://doi.org/10.33571/revistaluciernaga.v11n21a5
}

\section{Resumen}

El artículo presenta la reflexión teórica, resultado de investigación, acerca del fenómeno mediático denominado "videocolumnismo". Se exponen algunos de los aspectos históricos de aparición de la prensa en Occidente, proposiciones acerca de la esfera de lo público y la Modernidad, el modelo clásico de periodismo de opinión y las apropiaciones tecnológicas por parte de usuarios que se mueven en el escenario de la esfera pública virtual. Al final del escrito, se muestran las continuidades y discontinuidades del columnista de opinión clásico frente al videocolumnista como figura del comentario político en línea.

Palabras clave: periodismo de opinión; esfera pública digital; retórica online; sociedad de la información.

Recibido. Marzo 20, $2019 \quad$ Aceptado. Marzo 26, 2019

* Comunicador social-Periodista, Universidad de Antioquia; Magíster en Historia. Candidato a Doctor en Ciencias Humanas y Sociales, Universidad Nacional de Colombia. Profesor asistente de Universidad del Tolima. Orcid. http://orcid.org/0000-0003-0437-4395 ; e-mail: cagaviriac@ut.edu.co

** Comunicador Social y Periodista, Universidad Surcolombiana; Especialista en Gerencia de Recursos Humanos, Universidad Jorge Tadeo Lozano; Magíster Conflicto Territorio y Cultura, Universidad Surcolombiana. Doctorando en Comunicación de la Universdiad de La Plata -Argentina. Profesor asistente de la Universidad del Tolima. Orcid.http://orcid.org/0000-0002-6786-0940; e-mail: dapolop@ut.edu.co 


\title{
VIDEO-COLUMN FORMAT. Challenges for the opinion journalism
}

\author{
Cesar Augusto Gaviria Cuartas * \\ Diego Alberto Polo Paredes** \\ DOI: https://doi.org/10.33571/revistaluciernaga.v11n21a5
}

\section{Summary}

The article presents the theoretical reflection from results of a research focused on the media phenomenon known as "video-column". It presents some of the historical aspects raised in the occidental press, proposals about the sphere of the public and Modernity, the classic model of opinion journalism and the technological appropriations on the part of users who move in the scenario of the virtual public sphere. At the end of the paper, the continuities and discontinuities of the traditional opinion columnist are shown as opposed to the video columnist as an actor on the online political opinion.

Key words: opinion journalism; digital public sphere; rhetoric online; information society.

Received. March 20, $2019 \quad$ Accepted. March 26, 2019

* Comunicador social-Periodista, Universidad de Antioquia; Magíster en Historia. Candidato a Doctor en Ciencias Humanas y Sociales, Universidad Nacional de Colombia. Profesor asistente de Universidad del Tolima. Orcid. http://orcid.org/0000-0003-0437-4395 ; e-mail: cagaviriac@ut.edu.co

** Comunicador Social y Periodista, Universidad Surcolombiana; Especialista en Gerencia de Recursos Humanos, Universidad Jorge Tadeo Lozano; Magíster Conflicto Territorio y Cultura, Universidad Surcolombiana. Doctorando en Comunicación de la Universdiad de La Plata -Argentina. Profesor asistente de la Universidad del Tolima. Orcid.http://orcid.org/0000-0002-6786-0940 ; e-mail: dapolop@ut.edu.co 


\title{
VIDEOCOLUNISMO. Desafios para o jornalismo de opinião
}

\author{
Cesar Augusto Gaviria Cuartas * \\ Diego Alberto Polo Paredes** \\ DOI: https://doi.org/10.33571/revistaluciernaga.v11n21a5
}

\section{Resumo}

O artigo apresenta a reflexão teórica, resultado da pesquisa, sobre o fenômeno midiático conhecido como "videocolunismo". Apresenta alguns dos aspectos históricos do surgimento da imprensa no Ocidente, proposições sobre a esfera do público e da Modernidade, o modelo clássico do jornalismo de opinião e as apropriações tecnológicas por parte dos usuários que se movem no cenário da esfera pública virtual. No final do texto, as continuidades e descontinuidades do clássico colunista de opinião são mostradas em oposição ao vídeo colunista como figura do comentário político online.

Palavras-chave: jornalismo de opinião; esfera pública digital; retórica online; sociedade da informação.

Recebido. Março 20, $2019 \quad$ Aceitado. Março 26, 2019

* Comunicador social-Periodista, Universidad de Antioquia; Magíster en Historia. Candidato a Doctor en Ciencias Humanas y Sociales, Universidad Nacional de Colombia. Profesor asistente de Universidad del Tolima. Orcid. http://orcid.org/0000-0003-0437-4395 ; e-mail: cagaviriac@ut.edu.co

** Comunicador Social y Periodista, Universidad Surcolombiana; Especialista en Gerencia de Recursos Humanos, Universidad Jorge Tadeo Lozano; Magíster Conflicto Territorio y Cultura, Universidad Surcolombiana. Doctorando en Comunicación de la Universdiad de La Plata -Argentina. Profesor asistente de la Universidad del Tolima. Orcid.http://orcid.org/0000-0002-6786-0940 ; e-mail: dapolop@ut.edu.co 


\section{Introducción}

En 2016, en medio del maremágnum de sucesos que representó para Colombia el período previo al Plebiscito por la Paz, adquirieron protagonismo comentaristas colombianos que emplearon plataformas virtuales -particularmente Youtube- para evaluar avances y alcances de los acuerdos de La Habana entre el gobierno de Juan Manuel Santos y la guerrilla de las Farc. Aunque al final el resultado del Plebiscito del 2 de octubre sería tan sorpresivo como lo fue el Brexit en Inglaterra y lo que sería luego el triunfo de Donald Trump en Estados Unidos (de allí la inclusión del término 'posverdad' en el Diccionario Oxford [2], dicho contexto de la política nacional vería la aparición de los "videocolumnistas" [3] quienes, además de intensificar las discusiones de la opinión pública doméstica en torno al proceso de paz, representaron el germen de un nuevo agente mediático que, trascendiendo el cliché del youtuber como figura del ocio pre-adolescente (Aran-Ramspott, Fedele y Tarragó, 2018), se concentra en la apropiación de elementos del periodismo de opinión tradicional y diversas prácticas propias de la interactividad propiciada por las tecnologías de la información y la comunicación.

¿Quién hubiese imaginado hace un par de décadas que Facebook, Twitter y Youtube se iban a convertir en importantes instituciones de la esfera pública del presente? (Dahlgren, 2012).

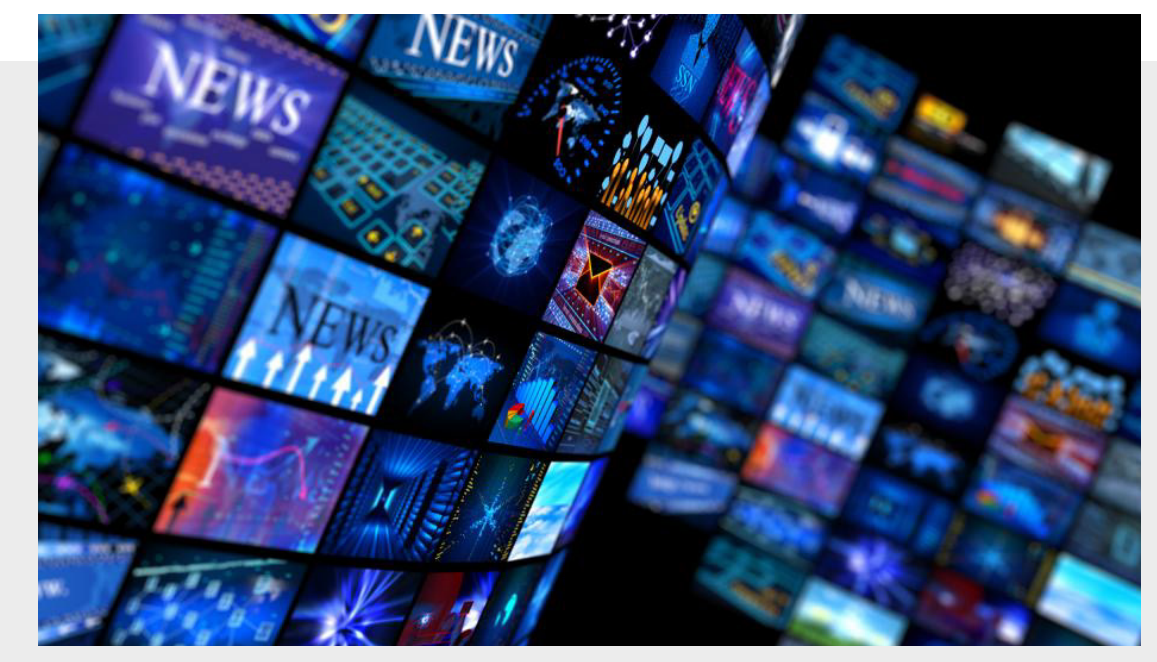

Imagen: https://bit.ly/2VreVFT

Precisamente, este escrito [1] plantea una reflexión sobre aspectos del clásico opinador de prensa en comparación con el comentarista audiovisual digital, en particular porque este fenómeno mediático del denominado videocolumnismo esbozó en 2016, avant la lettre, los rasgos de recientes formas del opinar públicamente [4] en la esfera pública digital. Aunque últimamente reconocidos columnistas de prensa escrita han empezado a hacer presencia audiovisual online, es pertinente establecer los que fueron elementos fundantes del videocolumnismo a partir del análisis de dos canales de Youtube generados por prosumidores [5] digitales colombianos que se integraron al 'boom' opinativo 
digital surgido en el contexto del Plebiscito por la Paz-, período durante el cual las utilidades de las tecnologías contemporáneas de comunicación se relacionaron con dos creaciones insignes de la modernidad en Occidente: la esfera pública liberal y el clásico periodismo de opinión.

\section{Algunas consideraciones históricas}

La aparición de la imprenta de tipos móviles de Johann Gutenberg en Alemania a finales del siglo XV generó una serie de cambios paulatinos, no solo técnicos, sino también de orden social y cultural que tendrían repercusiones en distintas sociedades europeas. De los cambios que Elizabeth Eisenstein (1968) planteó acerca de los efectos sociales y políticos que la imprenta trajo inicialmente al viejo continente, particularmente se pueden destacar aquellos que aportaron valores constitutivos de lo que se conoce como esfera pública moderna: aumento del alfabetismo, crecimiento del protestantismo, creación de nuevas profesiones, separación de lo sacro y lo secular, intensificación del deseo de libertad y recrudecimiento de la censura. Posteriormente, el proceso de modernización de la ciencia y la técnica en los siglos XVIII y XIX en Europa, llevaría al aumento de las fábricas, el surgimiento de grandes urbes, la explosión de la libertad de expresión y la cultura de masas (De Sola Pool, 1993).

Es decir, la imprenta desató un permanente proceso social y cultural que consolidó prácticas en torno al libro impreso y la divulgación periodística de acontecimientos de relevancia, lo que daría el primer gran impulso a la sensación de mayor rapidez, eficacia y amplitud de la información (Villamarin, 2011).

En varios sectores de Europa fue tal el ímpetu del capitalismo impreso luego de la invención de Gutenberg (Anderson, 2006), que muchos ciudadanos comunes y corrientes fundaron periódicos "no oficiales" sobre cuestiones políticas, al punto que hoy sigue vigente la pregunta si dicha explosión impresa fue una "trivialización" de los problemas políticos del momento o, por el contrario, ayudó al "ingreso de la política nacional en la vida cotidiana" (Briggs y Burke, 2002, p. 108).

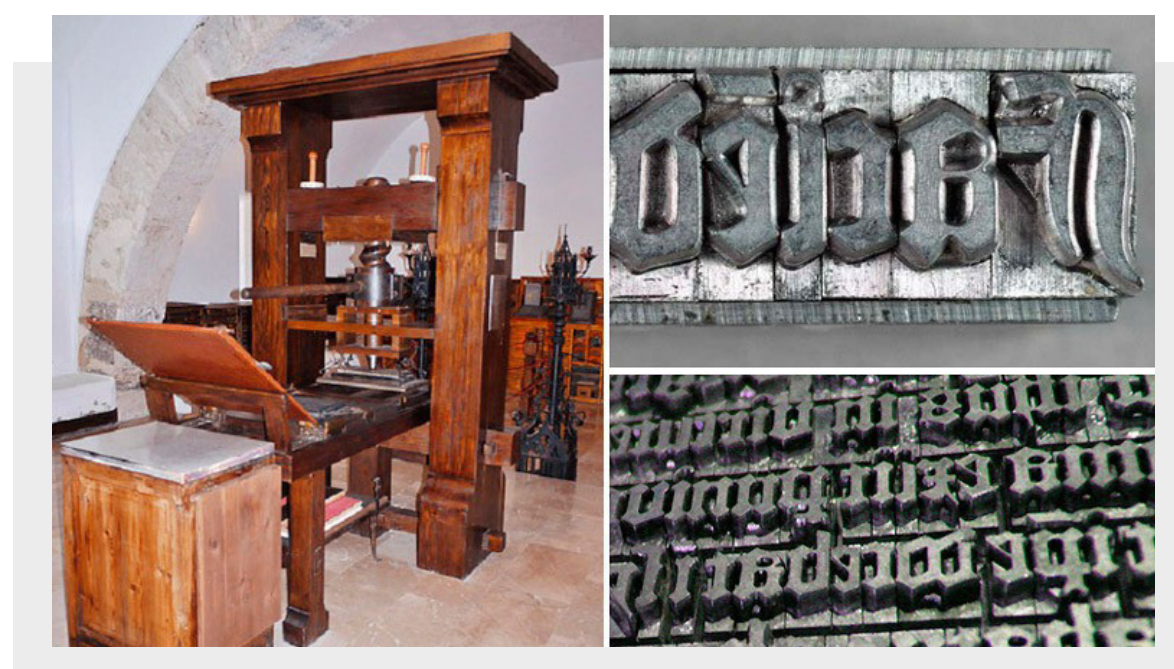

Tomada de: https://bit.ly/2ruBheG 
Caso prototípico sería el de Martín Lutero quien a pesar de no ser propiamente un "periodista", utilizó todos los géneros -el formato académico, la sátira, e incluso el libelo-, para sacar máximo provecho al "regalo divino" que era la imprenta del momento. Lutero marcaría el camino de la naciente labor cuando aceptó el oficio de escribir como si fuese una "misión apostólica complementaria a la predicación", ya que orientó sus escritos a capas sociales específicas -nobles, clérigos, campesinos- "según el interés del momento" (Alvarez, 2004, p.30).
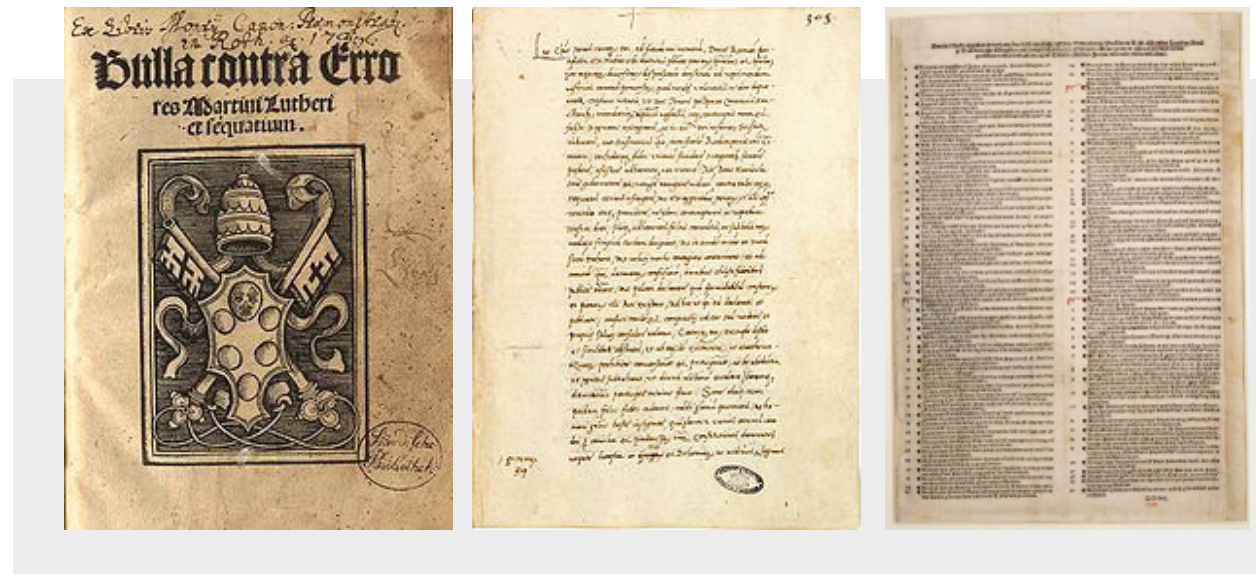

Tomada de: https://bit.ly/2qlicWv

Hacedores de opinión como Lutero paulatinamente aportarían al surgimiento del prototipo de la esfera moderna de lo público escenificada a lo largo de los siglos XVII y XVIII en espacios de debate en salones y cafés de Londres y París, donde se evidenciaron los avances de un periodismo de fuerte carácter doctrinario. R.R. Palmer explica que en esa época las personas que leían y hablaban con frecuencia sobre cuestiones políticas, adquirieron "un sentido cada vez mayor del interés público y se creía que las mejoras que se esperaban no había que dejarlas a la cerrada operación del gobierno, sino que debían ser legítima preocupación de todos" (citado por Muñoz-Alonso, 1992, p.39).

Aunque durante esta etapa el oficio del periodismo no era reconocido como parte fundamental de los sistemas de gobierno representativo -ni el periodista como designación de quien lo ejerce-, la mayoría de estos periódicos ponían en consideración de sus lectores temas dedicados a la filosofía, la moral, las ciencias y la política sustentados en el deseo de desarrollar el uso público de la razón, la libertad de expresión y la abierta discusión de ideas. Esto significó igualmente que la prensa y la labor del periodista -casi desde el momento mismo de su aparición- generara cuestionamientos ambivalentes en diversos sectores de la opinión pública: mientras hubo quienes consideraran a los periódicos como importantes "motores sociales" de la opinión, no faltaron quienes tildaran a estos redactores de ser "escritorzuelos de periódicos para la canalla" (Briggs y Burke, 2002, p.130-132).

Ello era el producto lógico de la materialización de la disposición liberal interesada en fortalecer la esfera pública teniendo como correlato los rasgos distintivos del periodismo de la época. En tal sentido, la discusión pública era "el medio" para librar la polémica nutrida por la información de la prensa escrita. De allí se desprende la definición de "publicidad" que Jurguen Habermas (1985) relaciona con el conocimiento, la circulación abierta, el debate de ideas y el discernimiento público. Si se comprende que para la época "la publicación de un 
periódico político era equivalente en importancia a un compromiso en la lucha por un espacio de libertad de opinión pública, por la esfera de lo público como principio" (Habermas, 1985, p.128), puede entenderse que haya tomado cuerpo el primer modelo de periodista de opinión como señal de la transformación de la sociedad a partir de la discusión pública de ideas en un espacio centralizado y normatizado.

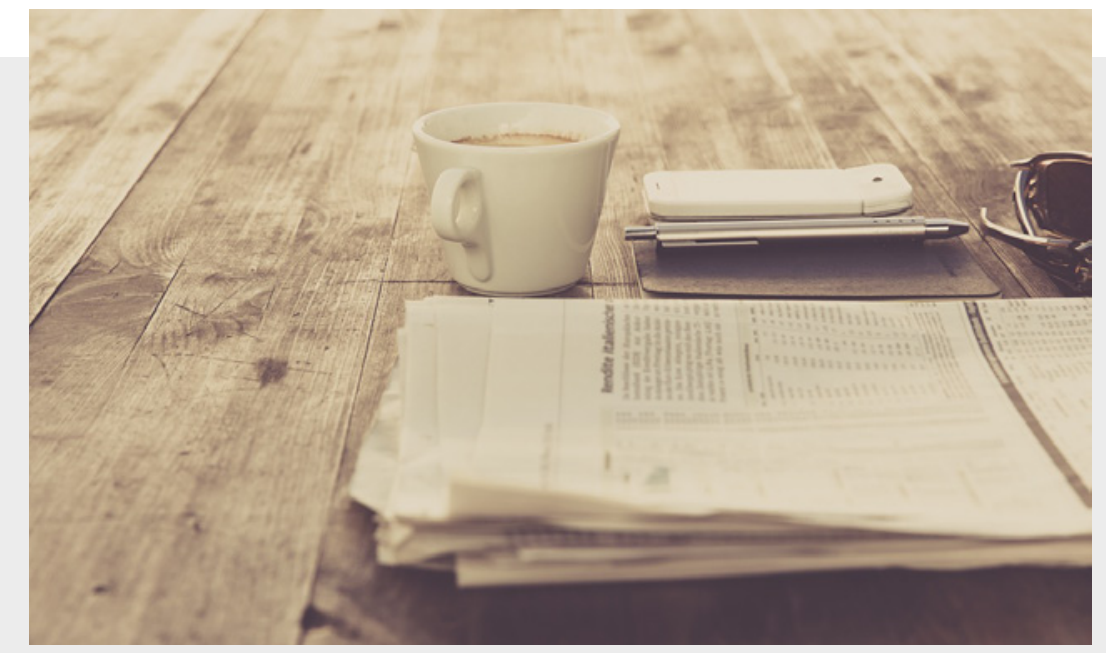

Por entonces, el debate racional de las ideas promovido por editores y articulistas de la prensa implicaba asumir los alcances de la opinión planteada ante una audiencia dispuesta a atender las justificaciones de estos denominados "publicistas". Ya lo escribía el poeta y dramaturgo Friedrich Schiller en 1782:

"El público lo es todo para mí; mi escuela, mi soberano, mi amigo fiel. A este tribunal, y solo a este, me someteré"

(citado por Van Horn Melton, 2009, p.16).

Dicho espíritu inspiró la defensa que Voltaire hizo de Jean Calais en su Tratado sobre la Tolerancia, en 1763 [6], e incluso pervivió en expresiones posteriores como la carta "Yo acuso" del también francés Emile Zolá [7].Estas efemérides de la esfera pública moderna coinciden en cuatro aspectos propios del primigenio periodista de opinión: llevar conocimiento a los sitios donde predominara la ignorancia; alcanzar la verdad por vías racionales; actuar para generar cambios políticos y sociales; y mostrar responsabilidad y sometimiento a las leyes públicas.

Sin embargo desde mediados del siglo XIX ese periodismo encendido e incendiario, lleno de ideas moralistas o vanguardistas, fue decayendo para darle paso a un periodismo más moderado, más formateado, más profesional. El mismo Honoré de Balzac, en 1843, alertaba sobre el aparente deterioro del periodismo de su tiempo ante el debilitamiento de la figura del publicista tradicional: "Del generalizador sublime, del profeta, del pastor de ideas que fuera antes, del publicista no queda ya más que un hombre ocupado de los despojos de la actualidad". Y más adelante él mismo agrega: "El publicismo era como un gran espejo concéntrico: los publicistas de hoy en día lo han hecho pedazos y cada uno de ellos tiene un trozo que hacen brillar a los ojos de la muchedumbre" (2009, p.43). 
Deudor de "la exigencia normativa del deber de instrucción" (Habermas, 1985) propio del liberalismo cultivado particularmente en el siglo XVIII, el escritor político tenía la misión de orientar a la mayor cantidad posible de lectores a partir de la fuerza de sus ideas. Era la argumentación racional la que protagonizaba el escenario del debate sobre asuntos públicos. Pero con el fortalecimiento de las nuevas tecnologías de la información y la comunicación se ha debilitado esa figura del opinador que asume la centralidad del "servidor público", para darle paso a prácticas de expresión online que otorgan licencia para expresarse libre y autónomamente, a gentes que no siempre cumplen con el ideal de racionalidad que caracterizó al clásico periodista de opinión.

\section{La opinión convertida en retórica online}

Los análisis de corte habermasiano suelen entender la abundancia de las opiniones de los comentaristas políticos digitales como el producto de los ambientes creados por la cultura capitalista basados en el intercambio de gustos e inclinaciones, modas y suposiciones (Dader, 1992; Dimitriu, 1997); contextos donde predominan "relaciones sociales inspiradas en obligatoriedades típicas de grupos donde las normas de acción pública tienen más flexibilidad" como la familia, los amigos o los coetáneos (Habermas, 1981). No obstante, los videos de este tipo de prosumidor cargados de aseveraciones, acusaciones, negociaciones y reconsideraciones políticas, son, más bien, el resultado de la capacidad humana de anticipar contextos de interacción con otros frente a un asunto público, entreviendo las características generales de un auditorio en línea. Este ejercicio incluye la disposición de los ciudadanos prosumidores a someter a discusión lo que consideran válido o no, pues han ensayado sus expresiones ante imaginarias reacciones de sus potenciales oyentes (De Sola Pool, 1993).

Ubicado en una perspectiva economicista antes que sociológica, Alvin Toffler (1980) había vislumbrado que las transformaciones técnicas llevarían al advenimiento de una época ("la tercera ola") protagonizada por el prosumo, una actitud capaz de disolver la línea entre el productor y el consumidor implantada por el industrialismo ("la segunda ola"). Esta "tercera ola" sería una etapa en la que el público "se desmasifica" al articularse con artefactos técnicos que facilitan la apropiación de la información. De allí que intuyera -a finales de la década de los 70 del siglo XX- que las grabadoras en video harían realidad "que cualquier consumidor se convierta además en productor de su propia imaginería" (Toffler. p. 169). Hoy día la fuerza de este pronóstico es tal que, en el caso de Youtube, es común relacionar el nombre de un canal con quien lo produce. Aunque Toffler obviamente no describió al prosumidor digital de nuestros días, su propuesta tiene aplicabilidad en un período en el que las gentes ya no se limitan a ser simples receptores y consumidores pasivos de informaciones en línea, sino emisores y productores activos. Son consumidores y productores -"prosumidores"- motivados por su deseo de comunicar virtualmente información de manera activa y reticular.

La demostración de lo anterior se puede encontrar en los meses previos al Plebiscito por la Paz de 2016, período en el que se crearon los primeros canales de youtubers colombianos que se enfocaron en temáticas políticas y en hacer públicas sus consideraciones sobre asuntos del partidismo nacional, trascendiendo con ello los anecdotarios personalistas juveniles del fenómeno 
youtuber hasta entonces conocido. Dos de los canales que sobresalieron en este contexto fueron La Pulla[8] y Me llamo Wally [9], dos canales en los que quedaron perfiladas las primeras características del videocolumnista originario.

En general, el análisis de ambos canales permite establecer, por ejemplo, que cada video estaba determinado por algún hecho o circunstancia política particular, a partir del cual se traían a colación diversos elementos comunicativos que el prosumidor digital considerara conexo. Es la versatilidad técnica que ofrece Youtube la que posibilita -en diversos grados-, la mezcla de contenidos políticos con el humor y diversos temas livianos de la "cultura pop" para crear un arsenal discursivo que le da carácter informal al mensaje que llega a los públicos. Esto puede implicar una fuerte inclinación por hibridar el análisis político con el infoentretenimiento, que en ocasiones lleva, incluso, al uso de estereotipos inspirados en particularidades culturales ya sea empleando el acento distintivo de algún lugar de Colombia o usand o frases típicas de ciertas regiones del país.
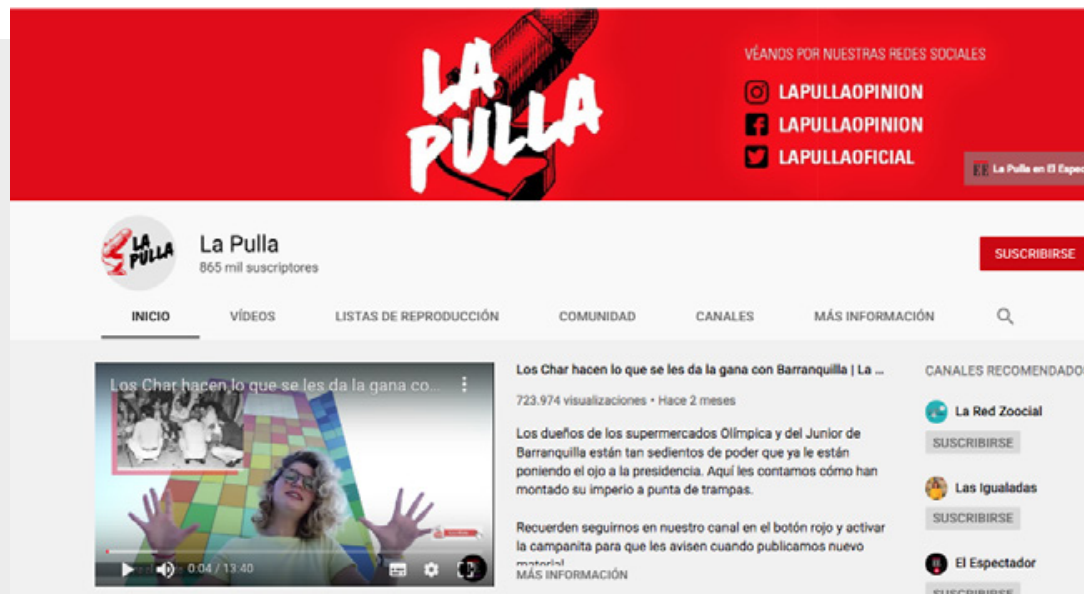

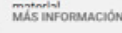

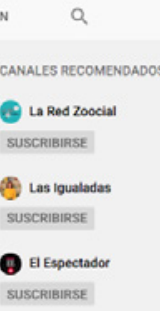

Sin embargo, la caracterización de estos agentes comunicativos permite establecer también sus particularidades. Específicamente, La Pulla es el ejemplo colombiano de lo que podríamos tipificar como el youtuber periodista, aquel prosumidor en el que un periodista (o grupo de periodistas) toma a Youtube como canal alternativo a los medios tradicionales con el fin de hacer públicas las consideraciones que por razones editoriales o corporativas no encuentran espacio en empresas informativas de renombre.

Este canal se basa en la compilación de antecedentes de un hecho puntual, la selección de titulares de distintos medios nacionales, la indagación y confrontación de información entremezclándolos con actitudes burlescas de su presentadora cuando hace referencia a la realidad política nacional. Aunque puede tener una tendencia ideológica que inclina la balanza discursiva hacia un lado del espectro político, el canal hace lo posible por limitarse a la contundencia de los hechos relacionados con el caso.

Por su parte, Me llaman Wally esboza lo que identificaríamos como el youtuber comentador, el ciudadano que, sin provenir de las escuelas de periodismo, se da la licencia de generar opinión a partir del consumo permanente de noticias de política nacional. El principal objetivo de este canal es reusar información de distintos medios tradicionales para que otros ciudadanos conozcan y acojan las opiniones políticas de su productor. Este este espacio digital se percibe con 
mayor proclividad a mostrar una tendencia política particular, usando con frecuencia elementos comunicativos provenientes de la televisión, la música y las redes sociales virtuales como respaldo retórico a sus planteamientos acerca del proceso de paz.

Aunque el diseño discursivo fue distinto en estos canales, los contenidos de ambos giraron en torno a los puntos de vista que, directa o indirectamente, se relacionaron con el proceso de La Habana que ese momento pretendía concluir el sino trágico que ha golpeado a Colombia durante los últimos 60 años. Usando las facilidades del formato audiovisual, estos opinadores plantearon argumentos para esclarecer las dudas de un posacuerdo desconocido por la mayor parte de la gente y debilitar las justificaciones de un conflicto incorporado por años al imaginario de la nación. Eran consideraciones en las que se abordaron las preocupaciones y esperanzas acerca de los efectos del Acuerdo de Paz, el régimen político del país, e incluso los tabúes internos a la sociedad colombiana que en los últimos años se han usado cotidianamente para interpretar la dinámica política nacional.

Tradicionalmente la argumentación de base racionalista ha considerado al "debate" como un intento serio de tener un diálogo crítico regulado y destinado a resolver una diferencia de opinión - expone Frans H. van Eemeren (2012)-; y al "cuasi-debate", un monólogo unidireccional calculado solamente para ganar el consentimiento de la audiencia en relación con los propios puntos de vista.

El primero se basa en principios de dialéctica en busca de la demostrabilidad, mientras el segundo sería ante todo una actuación oratoria en busca de la eficacia y la verosimilitud.

(Van Eemeren, 2012).

Si adoptáramos esa perspectiva, los discursos de los videocolumnistas serían cuasidebates que abastecen a una "minoría partisana" que usa la democratización de los medios digitales para ofuscar la verdad y manipular a la opinión pública (Keen, 2007).

"Las democracias, como uno de sus objetivos centrales, deberían promover tales discusiones críticas de puntos de vista. Solo si este es el caso, una participación estimulante en el discurso político puede mejorar la calidad de nuestras democracias"

(Van Eemeren, 2012, p. 27).

Con esto, se estaría pervirtiendo el papel de la opinión "publicada" para darle protagonismo a quienes no tienen como objetivo consciente el fortalecimiento del encuentro dialéctico, el fortalecimiento del ethos del argumentador, el mutuo reconocimiento del contrario (como lo fue en la esfera pública moderna), sino la argumentación marcada por una retórica que estimula particularmente el pathos -en términos de la teoría retórica aristotélica-.

Sin embargo, varias características del modelo racionalista del opinador surgido en la Edad Moderna (p. e. la distinción de la columna de opinión como un texto firmado por un ciudadano -periodista o no- respaldado por un prestigio adquirido; la publicación frecuentemente de consideraciones acerca de sucesos políticos o sociales de relevancia; y dar al público explicaciones de estos hechos y sus posibles consecuencias), se han combinado con las transformaciones técnicas de las últimas décadas, particularmente provocadas por las prácticas de consumo tecnológico, obligando a redefiniciones de lo conocido hasta ahora. 
La realidad es que estos comentadores políticos de la virtualidad en el siglo XXI, como agentes de opinión de la nueva esfera pública, han impulsado la renovación de las formas tradicionales del género de opinión a través de derivaciones contemporáneas como la videocolumna, ensanchando, de paso, los espacios de debate público.

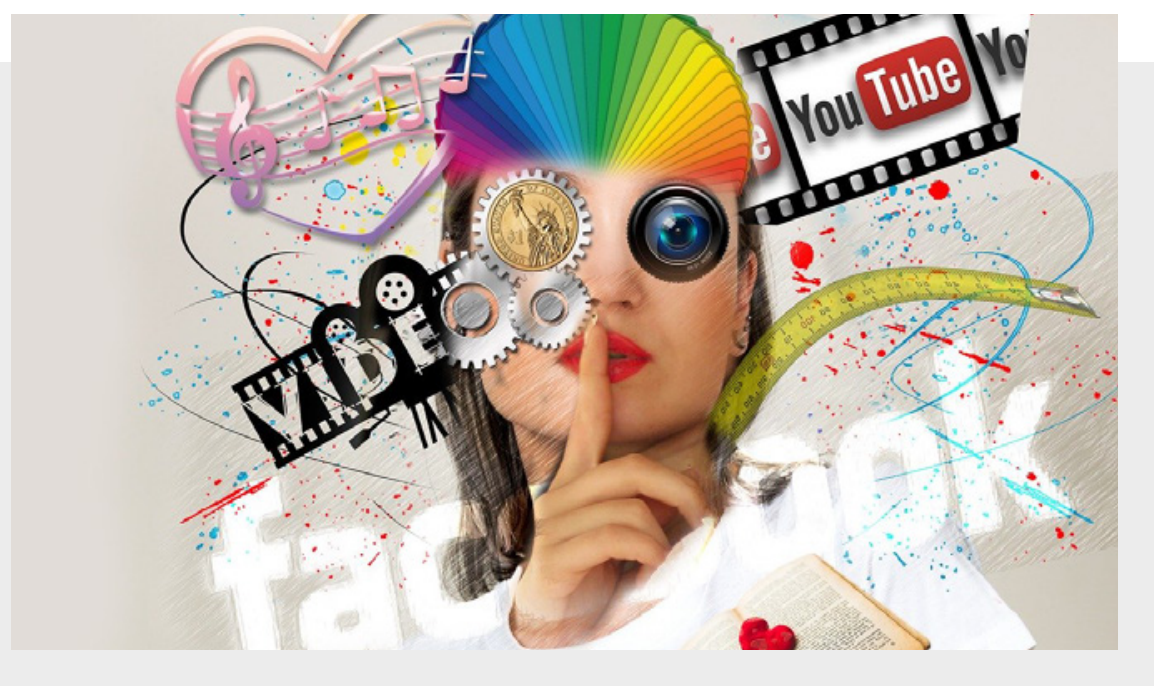

Y es que las actuales condiciones mediáticas digitales impulsan la adaptación de nuevas perspectivas que ajusten la presunción acerca de ambientes ideales de argumentación para darle una mayor fuerza a la apreciación de los contextos discursivos de la vida contemporánea "afectados por los sujetos, las emociones, el poder, la cultura y la ideología" (Reygadas y Haidar, 2001, p.123).

En términos discursivos, el videocolumnista, como sujeto enunciador, se caracteriza por cargar sus contenidos de intención persuasiva, adaptado al público destino que tiene en mente, y presentado en condiciones de masividad online. Con esto, la retórica política se convierte en una construcción cultural "que tiene una posición definida en la comunicación social y es percibida como tal construcción, a la cual están asociados los temas, las actitudes locutivas e ilocutivas de sus productores, los oradores políticos o autores de los mismos, y los efectos perlocutivos en los receptores, así como su influencia en la construcción de la sociedad". (Albadalejo, 2012, p. 53).

Hay que decir también que las formas de argumentación del videocolumnismo en línea pueden combinar, en distinta medida, aspectos de la lógica, la dialéctica, la lingüística y la retórica. Para cada uno de ellos corresponden, respectivamente, los criterios formales (demostrabilidad), los criterios trascendentales (aceptabilidad), los criterios lingüísticos (gramaticalidad) y criterios empíricos (comunicabilidad) (Reygadas y Haidar, 2001). Pero cuando el videocolumnista hace mayor énfasis en su capacidad retórica, hace de ella instrumento intencionado para la realización de actos de habla persuasivos de conjeturadas conversaciones en las que se crean verdades sociales, correspondiendo con "la realidad aceptada por una determinada comunidad lingüística" (López Eire, 2000, p.100). Ello confirmaría que en las condiciones comunicativas del presente, los sujetos que adelantan acciones retóricas de carácter político no buscan la acumulación de vínculos, sino su actualización o perfeccionamiento (Laborda Gil, 2012). 


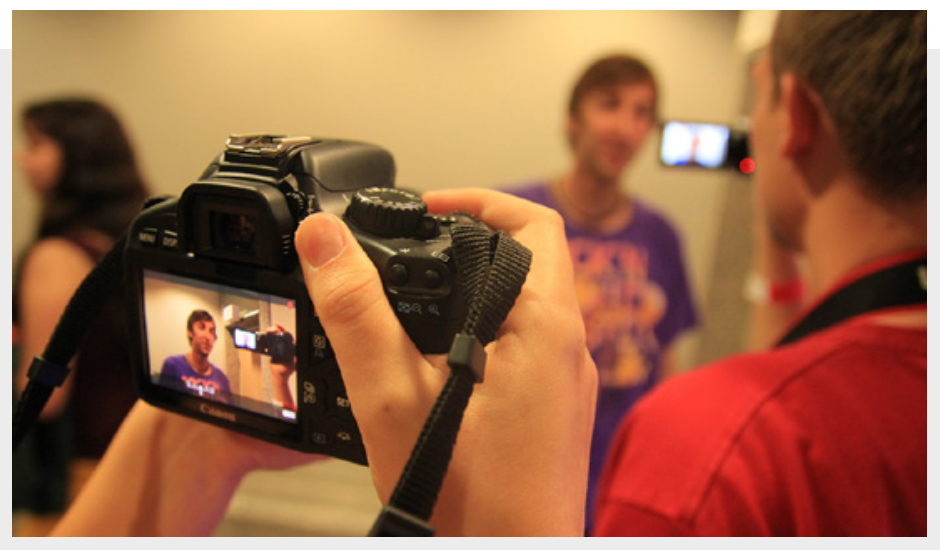

Muchas propiedades del discurso se relacionan, precisamente, con "las realizaciones estratégicas de los usuarios del lenguaje en acción" (Van Dijk, 2000, p.22). En este sentido, puede decirse que el discurso -como práctica social- y el enunciador, a partir de una secuencia de enunciados, confirman que se argumenta a partir de una posición evidente (apoyo, ataque, desautorización, provocación, etc.) asumida frente a un tema controvertido con el fin de que el enunciatario -un auditorio o interlocutores presenciales- acepte la forma de ver el asunto de debate. Por eso, el discurso de estos videocolumnistas surgidos en el contexto plebiscitario no pretendía el consenso ante un auditorio universal (como suele pretenderse desde la dialéctica moderna), sino aglutinar retóricamente a grupos específicos de oyentes.

Insertos en segmentos específicos de la sociedad, los comentadores digitales asumen a cada momento la tarea de convertirse en panegiristas de una tendencia política y de sus correligionarios, incluso sin que medie delegación ni contacto presencial con estos. Ello pone en cuestionamiento la tradicional teoría del Two-Step Flow -propuesta por Lazarfeld y Katz a mediados del siglo XX- pues no responde a los contextos comunicativos del presente.

Hoy tenemos que hablar de una teoría del Three-Step Flow (Gonzalez García, 2010), en el que personas que no son líderes en la vida real, llegan a serlo a partir del reciclaje de información proveniente de medios tradicionales y que luego redistribuyen a través de medios virtuales alternativos administrados por ellos mismos (p.e. blogs, fanpage, canales de Youtube, entre otros). En este nuevo modelo, la comunicación fluye: 1) de los medios tradicionales a los líderes internautas, 2) de los líderes internautas a los medios virtuales administrados por ellos, y 3) de los canales virtuales a los ciudadanos que frecuentan estos contenidos. Este es el marco de actuación del prosumidor de Alvin Toffler (1980) en versión digital, aquel sujeto que se beneficia de la instauración de una nueva sensibilidad social y cultural creada por las nuevas tecnologías (Turkle, 1997).

Lo anterior confirma que en muchas ocasiones los entornos sociales prácticos superan los modelos idealistas de la argumentación. El mismo Van Eemeren lo reconoce:

"Debido a una variedad de factores, la realidad argumentativa raramente se parece al ideal de una discusión crítica, como es de esperar a la hora de comparar cualquier realidad con un ideal" 
Ese es precisamente el actual desafío que enfrenta el modelo liberal de la esfera pública ante la avasalladora realidad comunicativa de hoy: redefinir muchos de sus conceptos básicos a partir de salvar la distancia, cada vez más amplia, entre el anhelo racional en sus orígenes y los contextos en los que se desenvuelven agentes digitales cuyas prácticas obligan a considerar ajustes según nuevos fenómenos comunicativos.

\subsection{Artistas de la esfera pública digital}

Raymond Williams (2001) explica que, en sus inicios, conceptos como "democracia", "industria" o "cultura" habían surgido débilmente; se usaban raras veces, pero luego se presentarían hechos o circunstancias que hicieron que su uso y significados iniciales se consolidaran o transformaran -en positivo o negativo-. Este proceso de cambio y asentamiento semántico de conceptos toma años o siglos, pero en cualquier caso se convierte en "un reconocimiento del efecto de estos cambios sobre la sociedad en su conjunto, que se transforma de manera similar" (Williams, 2001, p.14). Esto aplica para la aparición y afianzamiento de nuevos conceptos surgidos de las actuales condiciones sociales, políticas y económicas en las que los medios de información y las personas que acceden a ellos se relacionan con un entorno en el que las lógicas de producción, consumo y difusión de contenidos se modifican permanentemente.

A inicios del siglo XX, Charles Horton Cooley planteó que la expresión del pensamiento de unas personas a otras tiene su motivación en la expectativa del "efecto imaginado" que tendrá la reflexión interior en la mente de esos otros a quienes se dirige. Para Cooley, los artistas, hombres de letras y "las mentes productivas" se caracterizan por una especial necesidad de compartir con otros la expresión de su pensamiento. "Luchamos por comunicar a los otros esa parte de nuestra vida que intentamos desplegar en nosotros mismos" (Cooley, 2005, p.15).

Esto se verifica en los denominados colaboradores culturales (Williams, 1971), agentes que poseen "máxima importancia" por su activa participación en la cultura del presente. Estos creadores -entre los que se incluyen periodistas, críticos y comentaristas - buscan dar a sus obras una forma comunicable de la que obtienen "alguna satisfacción real", partiendo de lo que encuentra necesario decir o mostrar. "En sus diferentes maneras, el reportero, el comentarista y crítico, el actor y el artista necesitan una libertad garantizada para comunicar lo que, en términos de la propia concepción de sus trabajos, tienen que comunicar" (Williams, 1971 p.118).

Para Williams, una "buena sociedad" se construye a partir de que la consciencia de cada persona disponga de hechos e ideas cercanas a todo lo que "han visto, conocido y sentido realmente" los hombres que experimentan la realidad. Para Williams, el sistema de comunicaciones de cada momento se encuentra interiorizado en el colaborador cultural al punto que empleará en él, "lo mejor que puede", creativamente, un lenguaje común o convenciones conocidas para comunicarse con los demás. Su capacidad de hacer pública su obra dependerá del sistema de medios disponible, lo que responde a la explosión creativa que hoy se observa gracias a la "cercanía" de la tecnología: 
"Ahora que los ordenadores son las herramientas que utilizamos para escribir, diseñar, jugar con ideas, formas e imágenes, para crear secuencias de video y efectos musicales, para crear novelas interactivas e imágenes gráficas, se está desarrollando un nuevo conjunto de asociaciones intelectuales y emocionales, más parecidas a aquellas que aplicamos a los clavicémbalos que a los martillos. En la actualidad la cultura de la informática personal está dejando espacio a formas de conocer que dependen de la manipulación "concreta" de los pinceles y pinturas virtuales, de los bolígrafos y papeles virtuales"

(Turkle, 1997, p.81).

Esta creatividad del presente está relacionada con lo que se ha llamado las hipermediaciones, esto es, las transformaciones que van más allá del quehacer de los medios tradicionales, para dar paso a la trama de reenvíos, hibridaciones y contaminaciones en la tecnología digital. Es lo que respecta "a los receptores, del consumo activo, rebelde y contrahegemónico de las mediaciones"; es otra dimensión donde el usuario "colabora en la producción textual, la creación de enlaces y la jerarquización de la información" (Scolari, 2008, p.114).

Con esto, los videocolumnistas -ciudadanos que re-crean el formato de opinión basados en el uso de Youtube para comentar la política nacional-, se convierten no sólo en inéditos líderes de opinión sino en artistas de la opinión pública contemporánea que dedican sus creaciones a sentar posición acerca de hechos o personajes políticos del momento frente a porciones sociales específicas, rompiendo con ello la unidimensionalidad de los procesos comunicativos:

"Contrario a la práctica generalizada en los medios tradicionales que se dirigían a un público masivo e impersonal, el comunicador, hoy, debe hacerlo a las personas concretas con perfiles muy definidos o, al menos, a sectores claramente delimitados de una población, en lo que se ha llamado la segmentación de las audiencias"

(Asmar, 1997, p.64).

Orihuela (2002) indica que hoy día los medios dejaron de ser intermediarios para convertirse en desintermediarios, porque las prácticas de selección de temas y enfoques ya no son facultades exclusivas de medios y periodistas. Por tanto, se da una transformación de la unidireccionalidad a la interactividad, lo que supone ajustes en los modos de relación de medios y periodistas con los usuarios.

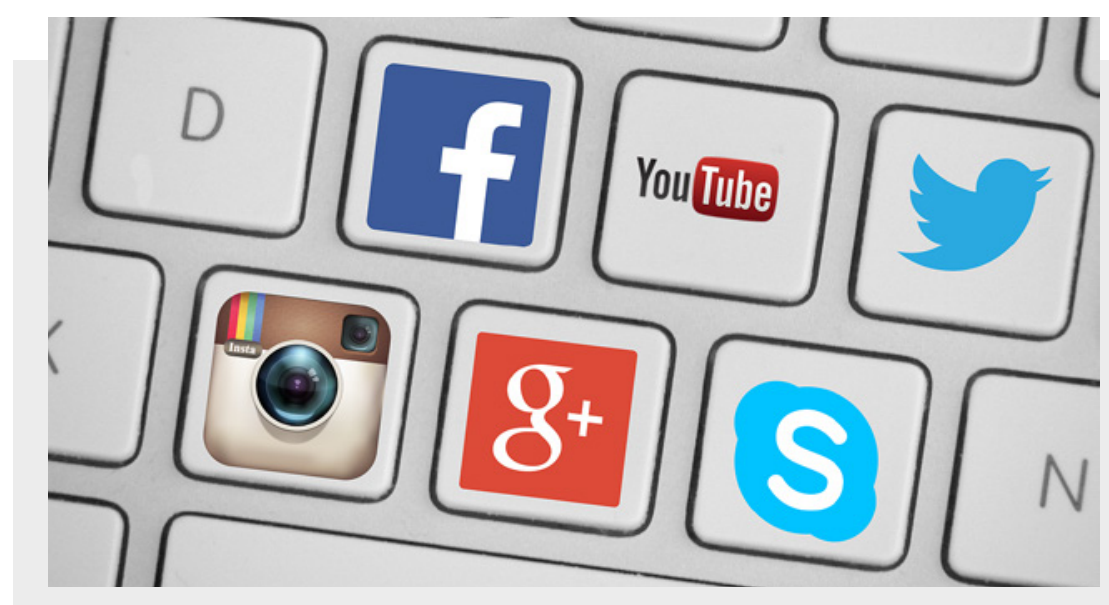


"Las plataformas de los medios sociales, lejos de ser productos acabados, son objetos dinámicos que van transformándose en respuesta a las necesidades de los usuarios y los objetivos de sus propietarios" (Van Dijck, 2016, p. 13).

Es decir, los medios masivos virtuales hacen parte de un cambiante ecosistema tecnocultural que a lo largo de la historia ha evolucionado en simultáneo con los usos y las necesidades de los públicos que le corresponden. Así, estos "artistas" de la opinión política, usan las cámaras de video como el nuevo acicate para exteriorizar el "tren de pensamiento" que hasta hace dos siglos estaba estimulado por las cartas y la presencia de los demás. Incluso puede afirmarse que los monólogos audiovisuales están reeditando la tendencia ilustrada que consideraba que "el pensar por sí mismo parece coincidir con el pensar en voz alta, exactamente igual que el uso de la razón equivale a su uso público" (Habermas, 1981, p.138).

La comprensión de las particularidades germinales de este columnismo audiovisual online, en especial por el fortalecimiento de las tecnologías de información y la autonomía adquirida por sus usuarios, lleva a considerar que aunque los asuntos políticos no han dejado de ser objeto de discusión de la esfera pública, el usuario se ha convertido en el eje de los procesos comunicativos -como afirma Scolari-. En la misma dirección, se puede afirmar que hemos pasado a las estructuras textuales no secuenciales, a las basadas en la hipertextualidad en las que se da mayor participación de los usuarios bajo la interactividad y la convergencia de medios y lenguajes en la multimedialidad.

En el plano de los lenguajes o plano comunicativo, el adjetivo multimedia identifica a aquellos mensajes informativos transmitidos, presentados o percibidos unitariamente a través de múltiples medios. En el plano de los medios, que por concretar, denominaremos plano instrumental, multimedia equivale a los "múltiples intermediarios" que pueden participar en la transmisión de un producto informativo, tanto si este producto es multimedia en el sentido comunicativo como si no lo es. (Xie, citado por Salaverría, 2001, p. 385)

En este contexto, hablar de multimedialidad, más que un campo cerrado y definido, es una invitación a las re-definiciones y las re-mediaciones en el ecosistema comunicativo digital. Para Scolari, el cambio en las estéticas narrativas se sustenta en las potencialidades tecnológicas en las que se presentan vínculos "de muchos a muchos", de forma reticular. "Los lenguajes comienzan a interactuar entre sí y emergen espacios híbridos que pueden dar origen a nuevas formas de comunicación. Esta idea que estamos delineando nos aleja de cualquier planteamiento extincionista" (Scolari, 2009, p.49).

Así, la videocolumna, como género emergente del entorno digital, materializaría los virajes narrativos basados en los juicios de valor de los usuarios. Y a su vez, las innovaciones incorporadas por el periodismo digital fortalecen la cultura participativa (Jenkins, 2008) y el ecosistema digital (Scolari, 2008) del presente. "En su evolución conjunta con las tácticas desarrolladas por sus usuarios habituales, un medio contribuye a moldear la vida cotidiana de las personas, y al mismo tiempo esta socialidad mediada se integra al tejido institucional de la sociedad en su conjunto". (Van Dijck, 2016, p. 13). 
Una mirada amplia nos muestra, en principio, que el columnista clásico y el primigenio videocolumnista se asemejan en la regularidad de sus publicaciones y la indisputable autoría de sus contenidos (escritos o audiovisuales). Asimismo, la estructura de sus razonamientos busca acercarse a un público determinado, razón por la cual sus mensajes muestran marcado carácter personalista, de tenor intimista. Por último, ambos tipos de opinadores coinciden en su empeño por abordar temas de relevancia sociopolítica, desplegando una comunicación generalmente argumentada que en ocasiones enfrenta consideraciones de pares que opinan sobre el mismo asunto y se dirigen al mismo público.

No obstante, también se encuentran diferencias que se desprenden del soporte material sobre el que se desenvuelve su labor: la figura del columnista tradicional surgió en una época en la que el papel era el sustento de un restrictivo código, limitación que obviamente no enfrenta el videocolumnista quien -como su nombre lo dice- echa mano de la versatilidad del soporte material audiovisual y multimedia de aparición reciente.

Como agente de la esfera pública moderna de fuerte sentido centralizado, el columnista clásico emplea un logos erudito con el que busca consolidar su ethos (talante) ante todo intelectual y su compromiso con el establecimiento de la verdad (típico de la Modernidad), de allí que sus razonamientos sean esencialmente dialécticos. Por su parte, el videocolumnista se desenvuelve como agente de una esfera pública virtual marcadamente fragmentada; se enfoca en percepciones caleidoscópicas respaldadas por la flexibilidad tecnológica que le facilitan un carácter ante todo creativo. De allí que su logos sea un medio para reforzar un pathos (ánimo) sobre el que se apoyan razonamientos principalmente retóricos, que le sirven de instrumento para presentar de manera sencilla no sólo las probabilidades de una situación sino la tendencia política que marca el derrotero de sus apariciones.

\section{A manera de conclusión}

Aunque la idea occidental de libertad de expresión y libertad de prensa nació antes de la denominada Sociedad Red (Castells, 2000), las dinámicas humanas digitales impulsan no sólo la aparición de nuevos usos y prácticas, sino la aparición de nuevos agentes que llevan a la redefinición de principios y conceptos clásicos de la democracia en Occidente. Si antes de la aparición de los medios electrónicos muchos científicos sociales renegaban del conformismo y la inactividad de los ciudadanos que no expresaban sus inconformidades abiertamente al público -señala De Sola Pool (1993)-, hoy, en vista de la dispersión en la producción facilitada por los medios digitales, se quejan de la falta de conciencia, la irracionalidad y el carácter atomizado de la sociedad del presente.

De allí que se encuentren profesionales inquietos ante la aparente desaparición del espíritu de la prensa del siglo XVIII como mediadora de la discusión pública, en consonancia con la posición crítica de Jurguen Habermas que ha culpado a los avances del industrialismo de haber convertido a la esfera pública moderna en simple medio "para una cultura del consumo" (1985, p.128). 
Habría que decir, más bien, que el carácter público es hoy más complejo si se observa detenidamente cómo cuestiones que ocurren en la vida offline saltan a la vida online, y viceversa, generando posibles interdependencias en ambos espacios de discusión pública.

"Los patrones de comportamiento existentes en la socialidad offline (física) se mezclan cada vez más con las normas sociales y sociotécnicas generadas en el entorno online, que adquieren así una nueva dimensionalidad"

(Van Dijck, 2016, p. 23).

Es decir, de no ser por esa sobre exitación opinativa, no sería posible cimentar una versión mucho más acotada de la libertad de expresión como baluarte renovado del periodismo contemporáneo. En este sentido, los medios digitales deben comprenderse como la arena en la que permanentemente se ajustan, desajustan y reajustan los modelos y las reglas de comunicación tradicional entre los humanos, particularmente si se tiene en cuenta que las herramientas tecnológicas de hoy empoderan a personas comunes y corrientes que en muchas ocasiones prescinden de los expertos y los especialistas que opinan, ratificando con ello el fin de las jerarquías y la verticalidad de la información en favor de la autocomunicación de masas (Castells, 2009).

Se entiende, entonces, que quienes en 2016 asumieron el rol de videocolumnistas desenvolvieron, ante terceros en masa, formas de liderazgo virtual en un momento preciso de una polémica política que generó interés en la ciudadanía de a pie -como sucedió durante los meses previos al Plebiscito por la Paz en Colombia-, aparentemente renunciando a la razón, pero en realidad planteando argumentos razonables, antes que racionales. Esa intención coyuntural los llevó a ellos (y a otros videocolumnistas) a utilizar las ventajas y potencialidades de las herramientas multimediales para usar y reusar información, combinada con estrategias retóricas que sirvieron para hacerse visible a la masa anónima y amorfa que diacrónicamente consultaba su opinión en video.

Lo que experimentó -y sigue experimentando- el periodismo de opinión podría equipararse con la expansión de las publicaciones "no oficiales" que aparecieron en Europa en los siglos XVI y XVII que sirvieron para acercar la esfera política a la cotidianidad de las gentes del común. Igualmente, mientras el prototipo de columnista clásico fue producto de la mezcla del capitalismo impreso de inicios de la modernidad y el capitalismo industrial del siglo XIX, el videocolumnista sería el primer esbozo del opinador generado por el capitalismo informacional del siglo XXI. Así mismo, el videocolumnista, en su condición de prosumidor digital, sería la verificación de la transformación de la teoría de los dos pasos -two-step flow, en teoría de los tres pasos -three-step flow.

Claramente esto representa un escenario de importantes redefiniciones de orden epistémico y práctico en el periodismo. Epistémico, porque a este oficio en tiempos de internet le asalta la duda permanente acerca de si efectivamente se está ante un nuevo periodismo, o si por el contrario, es el mismo ejercicio acompañado de otras mediaciones. Y práctico, toda vez que sus estilos se ven obligados a modificarse debido a que el acceso a los datos es más fluido e impersonal. Ante esta preocupación de un sector del profesionalismo, habría que decir que así como la aparición histórica de una nueva invención técnica de 
comunicación no ha significado la completa desaparición de sus antecesores (Cervera Gil, 2004), también podría afirmarse que la crisis generada por la aparición del videocolumnismo no llevará al columnismo clásico a su desaparición sino a su fortalecimiento. Por ello -después de conocer el intelectualismo en la divulgación de información nacida tres siglos atrás y presenciar hoy día la aparición de opinadores audiovisuales online-, las reflexiones acerca de manifestaciones periodísticas en la esfera pública virtual (como el videocolumnismo) deberían comprender los actuales contextos comunicativos como posibilidad de consolidación de los principios democráticos de la información en el presente siglo.

\section{Referencias}

Alvarez, Jesús Timoteo (2004). Los medios y el desarrollo de la sociedad occidental. En: Historia del periodismo Universal. Carlos Barrera -coordinador-. España, Ariel, pp. $25-40$

Albadalejo, Tomas (2012). La retórica política y comunicación digital. La ampliación de la poliacroasis. En: Del Río Sanz, Emilio, Ruiz de la Cierva, M $^{a}$ del Carmen, y Albaladejo, Tomás (editores). Retórica y política. Los discursos de la construcción de la sociedad. España, Instituto de Estudios Riojanos, pp. 49-66

Anderson; Benedict (2006). Comunidades imaginadas: Reflexiones sobre el origen y la difusión del nacionalismo [1983]. México, Fondo de Cultura Económica

Aran-Ramspott, Sue; Fedele, Maddalena; y Tarragó, Anna (2018). Funciones sociales de los youtubers y su influencia en la preadolescencia. En: Comunicar, Revista Científica de Educomunicación. España, $N^{\circ}$ 57, v. XXVI, pp.71-80

Asmar, Patricia (1997). La Narrativa en Multimedia. Algunas implicaciones de las nuevas tecnologías en la formación de comunicadores. En: Palabra Clave, 55 (2), 55-72.

Briggs, Asa y Burke, Peter (2002). De Gutenberg a Internet: Una historia social de los medios de comunicación. España, Taurus

Castells, Manuel (2000). La era de la información: economía. sociedad y culᄀtura. Volumen I: La sociedad red. [1996]. Madrid, Alianza

poder. Madrid, Alianza
Cenvera Gil, Javier (2004). Comunicación social y generalización de la cultura de masas. En: Historia del mundo contemporáneo, siglos XIX-XX. Javier Paredes -director-. España, Ariel, pp. 780-801

Cooley, Charles Horton (2005). El yo espejo [1902]. En: CIC. Cuadernos de Información y Comunicación. Universidad Complutense de Madrid. No. 10, 2005, pp. 13-26

Dader, Jose Luis (1992). La personalización de la política. En: Muñoz-Alonso. Alejandro. et.al. Opinión pública y comunicación política. Madrid. Eudema. pp.351-367

Dahlgren, Peter (2012). Mejorar la participación: la democracia y el cambiante entorno de la web. En: Internet y el futuro de la democracia. Champeau, Serge e Innerarity, Daniel (compiladores). Barcelona, Paidós, pp. 45-67

De Balzac, Honoré (2009). Monografía de la prensa parisina: Los periodistas [1843]. Zamora. Comunicación Social

De Sola Pool, Ithiel (1993) Tecnologías sin fronteras: De las telecomunicaciones en la época de la globalización. México, Fondo de Cultura Económica

Dimitriu, Andrés (1997). Cuando las cosas son llamadas por su precio: del periodismo de opinión a la información como valor de cambio. En: Entel. Alicia - compiladora-. Periodistas: entre el protagonismo y el riesgo. Argentina, Paidós. pp. 217-231

Eisenstein, Elizabeth (1968). Some conjectures about the impact of printing on western society and thought: a preliminary report. The Journal of Modern History, Vol. 40, No. 1 (March), pp.1-56 
Gonzales García, María (2010). Los líderes de opinión o influentials en las redes sociales de Internet. Hacia el Three-Step Flow que defina los procesos de influencia personal en la Red. España, Memorias II Congreso AEIC Malaga 2010

Habermas, Jurgen (1981). Historia y crítica de la opinión pública: La transformación estructural de la vida pública [1962]. Barcelona. Gustavo Gili

(1985). La esfera de lo público. En: Dialéctica. Vol. 10. No. 17. México. UAP. pp. 123-130

Jenkins, H. (2008) Convergence Culture: La Cultura de la Convergencia: De los Medios de Comunicación. Madrid: CIC Cuadernos de Información y Comunicación

Keen, Andrew (2007). The cult of the amateur: how today's internet is killing our culture. Estados Unidos, Doubleday

Laborda Gil, Xavier (2012). De retórica: La comunicación persuasiva. Barcelona, UOC

Lévy, P. (2007). Cibercultura. La Cultura de la Sociedad Digital: Antrhopos. Orihuela, J. L. (2008). La hora de las redes sociales. Recuperado de http://www.luminpdf.com/files/1076763 2/nueva_revista_08.pdf

López Eire, Antonio (2000). Esencia y objeto de la retórica. España, Universidad de Salamanca

Monzón, Cándido (2008). El hombre espectador en la cultura de masas: Opinión pública y medios de comunicación. En: Capellán. Gonzalo-editor-. Opinión pública: Historia y presente. España. Trotta. pp. 207-225

Muñoz Alonso, Alejandro, Monzón, Cándido, et.al. (1992) Opinión pública y comunicación política. Madrid, Eudema

Rey, Germán (2014). Transformaciones de la cultura y variaciones de las políticas. Del ecosistema mediático al ecosistema digital en Colombia. En: Revista TELOS (Cuadernos de Comunicación e Innovación). Febrero -mayo. Recuperado de www.telos.es
Reygadas R., Pedro, y Haidar E., Julieta (2001) Hacia una teoría integrada de la argumentación. En: Estudios sobre las Culturas Contemporáneas, México, Universidad de Colima. Vol. 7, No. 13, junio, pp. 107-139

Salaverría, Ramón (2001). Aproximación al concepto de multimedia desde los planos comunicativo e instrumental. En: Estudios sobre el Mensaje Periodístico. (7), pp. 383-395.

Scolari, Carlos. (2008). Hipermediaciones. Elementos para una teoría de la Comunicación digital interactiva. Barcelona, España: Gedisa

(2009). Alrededor de las Convergencias. Conversaciones teóricas, divergencias conceptuales, y transformaciones en el ecosistema de medios. En: Signo y Pensamiento, 28(54), pp. 44-55.

Toffler, Alvin (1980). La tercera ola. Barcelona, Plaza \& Janes

Turkle, Sherry (1997). La vida en pantalla: La construcción de la identidad en la era de internet. Barcelona, Paidós

Van Dijk, Teun (2000). El discurso como interacción social. Barcelona, Gedisa

Van Dijck, Jose (2016). La cultura de la conectividad: Una historia crítica de las redes sociales. Buenos Aires, Siglo XXI

Van Eemeren, Frans H. (2012) Maniobras estratégicas en el discurso argumentativo. México, Plaza y Valdes

Van Horn Melton, James (2009). La aparición del público durante la ilustración europea. Valencia. PUV

Villamarin Carrascal, José (2011). La retórica en los artículos de opinión: Teoría, metodología y análisis de casos. Ecuador, Ciespal

Williams, Raymond (1971). Los medios de comunicación social. Barcelona, Península

(2001).Cultura y

sociedad, 1780-1950. De Coleridge a Orwell. Argentina, Nueva visión 


\section{Notas}

[1] Este artículo es producto de la investigación "Comunicación emotiva de videocolumnistas colombianos en el contexto político del Plebiscito por la Paz en $2016^{\prime \prime}$.

[2] 'Posverdad', palabra del año. El País (España). 17 de noviembre de 2016. Online:

http://internacional.elpais.com/internaci onal/2016/11/16/actualidad/147931626 8_308549.html

[3] Conferencias TED Colombia: "Llegó la hora del periodismo visceral", Maria Paulina Baena. 5 de enero de 2017. Consultado 10 de mayo de 2017. Online: https://www.youtube.com/watch?v=d3K nXm4ScXk - También en "Colombia es un país mojigato, yo digo lo que pienso $y$ ya": Adolfo Zableh. Kienyke. 4 de agosto de 2016. Consultado 12 de mayo de 2017. Online:

https://www.kienyke.com/historias/colo mbia-es-un-pais-mojigato-yo-digo-lo-que -pienso-y-ya-adolfo-zableh -

[4] En este escrito los diversos géneros de periodismo de opinión (editorial, crítica, comentario, entre otros) se entienden bajo el término "columna", es decir como un sólo género de opinión en el que un periodista (ciudadano profesional del área o no) presenta una posición personal basada en razonamientos o reflexiones acerca un hecho, personaje o cuestión de interés público.

[5] Aunque el creador de este término, Alvin Toffler (1980) no describió propiamente al prosumidor digital de nuestros días, vislumbró genéricamente al prosumidor, un sujeto capaz de disolver la línea entre el productor y el consumidor implantada por el industrialismo ("la segunda ola"), para darle paso a una época (la "tercera ola") en la que las gentes ya no se limitan a ser simples receptores y consumidores pasivos de bienes y servicios, sino emisores y productores activos. Una época en la que el público "se desmasifica" al articularse con artefactos técnicos que facilitan sus apropiaciones.

[6] Allí Voltaire dice estar animado por "un espíritu de justicia, de verdad y de paz" en pro de limpiar públicamente el nombre del condenado Calais ante "Europa entera".

[7] En 1898 Emilé Zolá imploraba a la humanidad verter luz en favor del capitán Alfred Dreyfus como "medio revolucionario de activar la explosión de la verdad y de la justicia". Afirmaba Zolá: "Mi ardiente protesta no es más que un grito de mi alma. Que se atrevan a llevarme a los Tribunales y que me juzguen públicamente".

[8] Canal de Youtube producido por un grupo de jóvenes periodistas profesionales encabezado por su presentadora Maria Paulina Baena. Desde su inicio ha estado respaldado por el periódico El Espectador. El formato usado por este canal es el monólogo de opinión apoyado en spots periodísticos relacionados con las argumentaciones planteadas.

[9] Canal de Youtube producido por el joven abogado Walter Rodríguez. La apertura de este canal data de diciembre de 2015. Aunque Rodríguez no proviene del mundo periodístico ni era reconocido masivamente antes de 2016, las producciones de este ciudadano se han desarrollado en el formato televisivo de opinión late night show.

Para citar este artículo:

Gaviria Cuartas, Cesar, y Polo Paredes, Diego Alberto (2019). VIDEOCOLUMNISMO. Desafíos para el periodismo de opinión. Revista Luciérnaga Comunicación. Vol. 11, Núm. 21. Pp 105 - 124.

DOI: https://doi.org/10.33571/revistaluciernaga.v11n21a5

OJS. http://revistas.elpoli.edu.co/index.php/luc/issue/archive Link. https://www.politecnicojic.edu.co/index.php/revista-luciernaga 